\title{
Efficiency of ventilated facades in terms of airflow in the air gap
}

https://doi.org/10.2478/sgem-2021-0014

received April 14, 2021; accepted May 11, 2021.

\begin{abstract}
The gradual exploitation of the natural environment has forced most developed countries to promote ecological solutions and the development of sustainable construction. Ventilated facades perfectly match into this trend, and with their appropriate design, they bring real energy savings. This paper analyzes numerically the influence of the inflowing air, mimicking the wind, on the efficiency of heat removal from the ventilated space and heat transmission by thermal radiation and conduction through the consecutive layers of the external wall. For the purpose of comparison, two variants of ventilated facade were adopted: open and closed joints, at different wind speeds prevailing outside. The results obtained show that in windless weather, the ventilated facade with open joints shows higher heat removal efficiency and thus lower heat transmission to the building interior. At higher wind speeds of $5 \mathrm{~m} / \mathrm{s}$, the open-joint and closed-joint ventilated facades achieve similar heat transfer efficiency, and the prevailing temperature inside the building for the two technologies is almost identical. Subsequent increments of incoming wind on the building result in minimal differences in the heat transmission to the building interior, representing changes of about $0.1^{\circ} \mathrm{C}$ at increments of another $5 \mathrm{~m} / \mathrm{s}$ of incoming wind. Conscious use of this facade technology, along with appropriate urban design of cities, can help reduce the energy needed to cool buildings during the summer period.
\end{abstract}

\footnotetext{
*Corresponding author: Krzysztof Schabowicz, Wrocław University of Science and Technology, Faculty of Civil Engineering, Department of Construction Technology, Wybrzeże Wyspiańskiego 27, 50-370 Wrocław, Poland, E-mail: krzysztof.schabowicz@pwr.edu.pl, ORCID: 0000-0001-6320-9539

Łukasz Zawiślak, Wrocław University of Science and Technology, Faculty of Civil Engineering, Department of Construction Technology, Wybrzeże Wyspiańskiego 27, 50-370 Wrocław, Poland, ORCID: 00000003-2828-5899

Pawet Staniów, Wrocław University of Science and Technology, Faculty of Civil Engineering, Wybrzeże Wyspiańskiego 27, 50-370 Wroctaw, Poland, ORCID: 0000-0001-6266-293X
}

Keywords: ventilated facades; heat transfer; heat transmission; CFD; numerical simulation; energy efficient facades.

\section{Introduction}

Gradual exploitation of the natural environment has forced most developed countries to promote ecological solutions, including lower energy consumption and promotion of renewable energy sources. In many European countries, the share of renewable energy is already over $50 \%$, with the Scandinavian countries being the pioneers in this statistic. The European Green Deal includes a goal for Europe to be a completely climate-neutral continent, a target to be reached in 2050. Figure 1 shows the share of renewable energy sources in each European country based on 2018 data.

Citing 2018 data from Eurostat, the energy split attributable to the buildings sector is $25.8 \%$ and services $14.2 \%$, which together amounts to $40 \%$ [1] of total energy consumption (Figure 2). Compared to 2016, this gives an increase of 0.8 percentage points.

The concept of environmentalism in construction has a place in sustainable construction, which aims to create buildings, with an eye to the future, that are non-polluting and user-friendly. In sustainable construction, there are several multi-criteria building rating systems, and these include BREEAM and LEED. Certification with these systems means having the lowest possible negative impact on the environment during the life cycle of a building. Both of these systems analyze similar components such as energy, water, building materials, and waste. The concept of reducing energy consumption is fundamental to sustainable construction. Buildings made in sustainable construction systems are characterized by high comfort of use of these buildings. The assessment of comfort of use shall be carried out through various indicator assessments [2].

One of the basic elements of energy efficient buildings is a properly constructed facade, which is the largest area of contact with the environment. The facade has to 


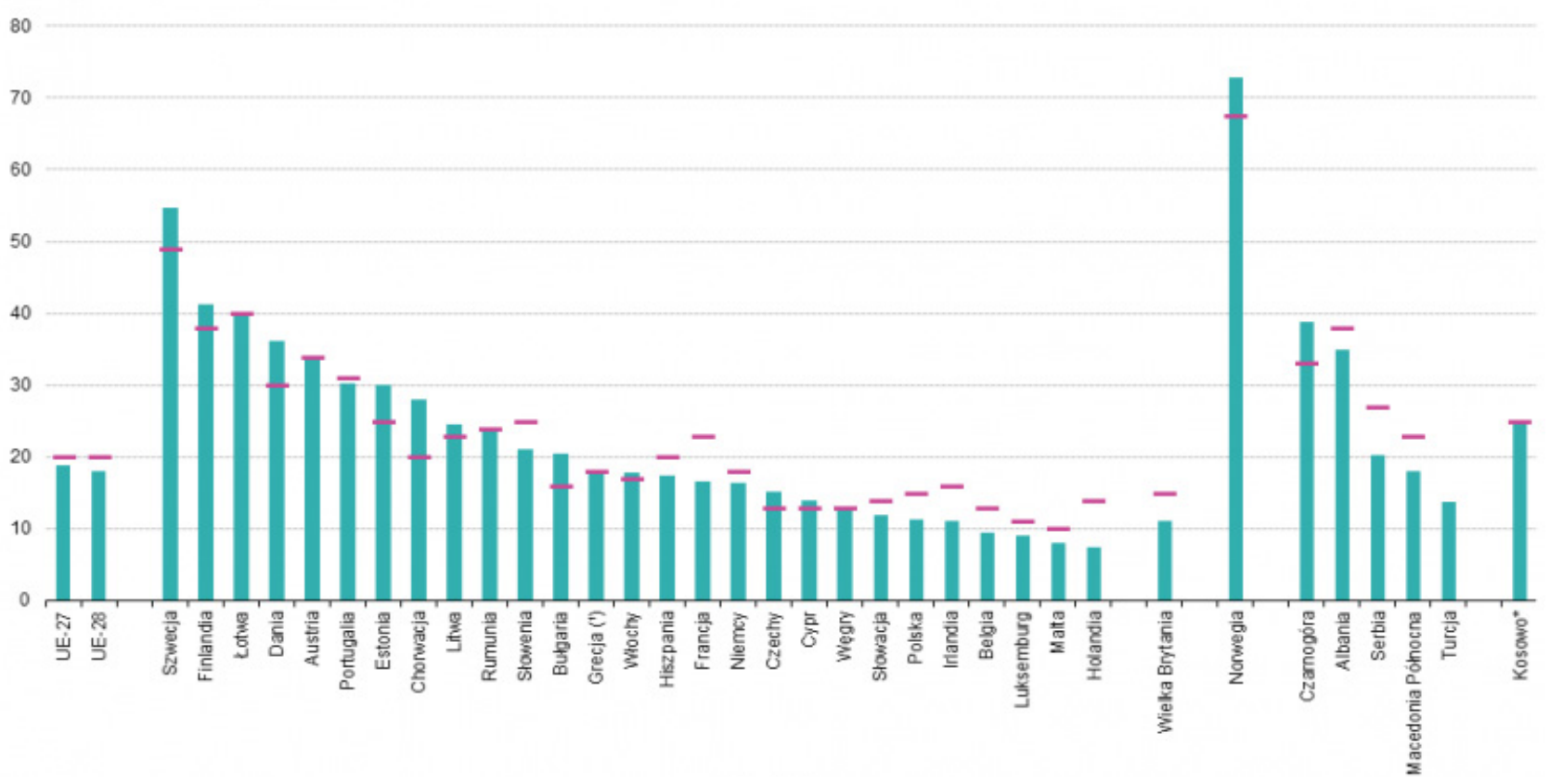

Figure 1: Share of energy from renewable sources, 2018 [1].

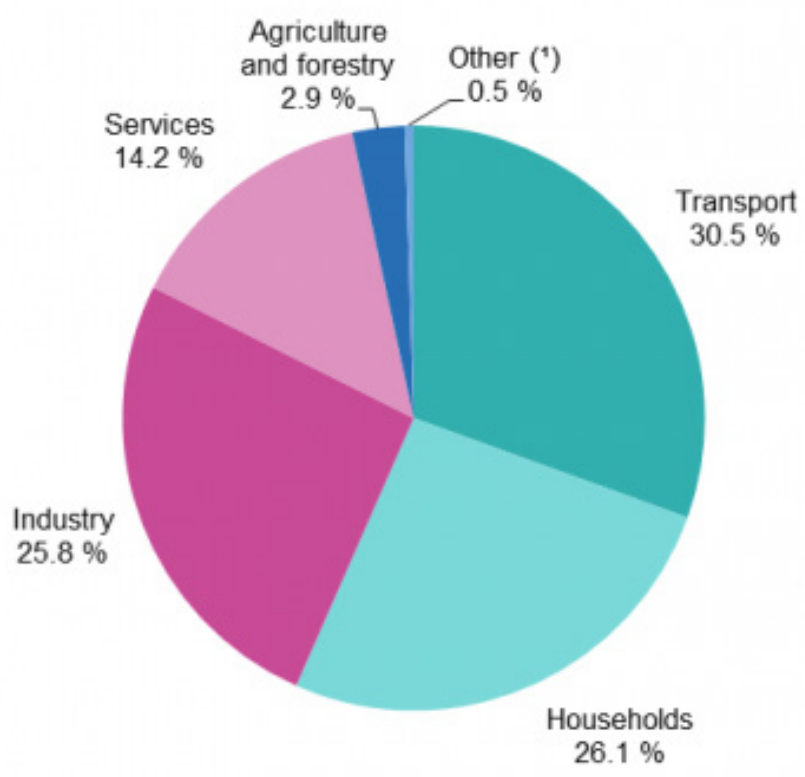

Figure 2: Percentage distribution of energy consumption by sector in 2018 [1].

protect the building from high and low temperatures, sunlight, wind, and precipitation. We define the facade as the surface layers of the external wall, including all its elements that extend beyond the external wall structure. In the case of a veneer, we speak only of its visual element, visible on the building.
We distinguish between several technical facade solutions:

- ETICS (External Thermal Insulation Composite System) facade, commonly known as light-wet method

- Traditional plasters

- Ventilated facade

A ventilated facade is an ideal solution for sustainable building. A ventilated facade is the technical solution for the top layer of an exterior wall consisting of an external facade cladding that is mechanically or adhesively attached to a substructure. The substructure is mechanically fastened to the exterior wall of the building through consoles. There are many suppliers of these systems on the market, ensuring that the requirements of the most demanding purchasers (e.g., in terms of Passive Houses) are met. Unfortunately, various regulations should be taken into account which may repeatedly prevent the use of these elements on facades (e.g., zoning plans in particular places or other regulations). External facade claddings used in ventilated facades can be made of various materials, e.g., fibre-cement boards, concrete boards, steel elements, ceramic elements, and other composite elements. External facade claddings are usually installed in accordance with the individual technical design of the facade and the requirements set out by the product manufacturer. They are nonload-bearing elements, bearing only their own weight 


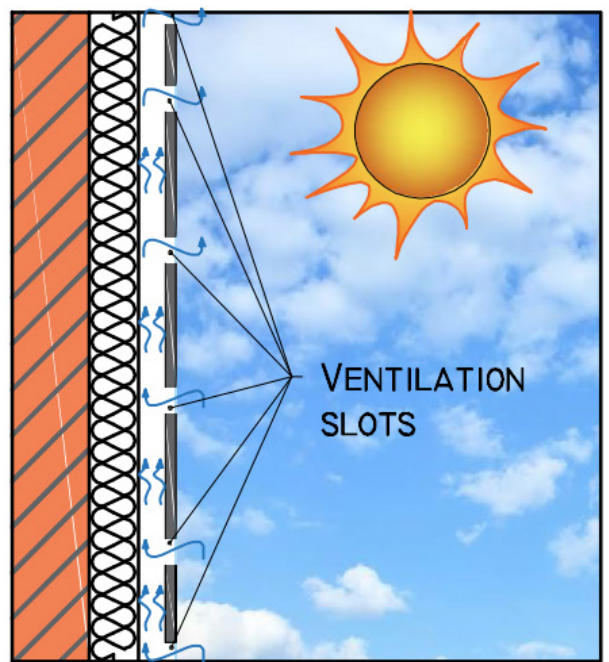

a)

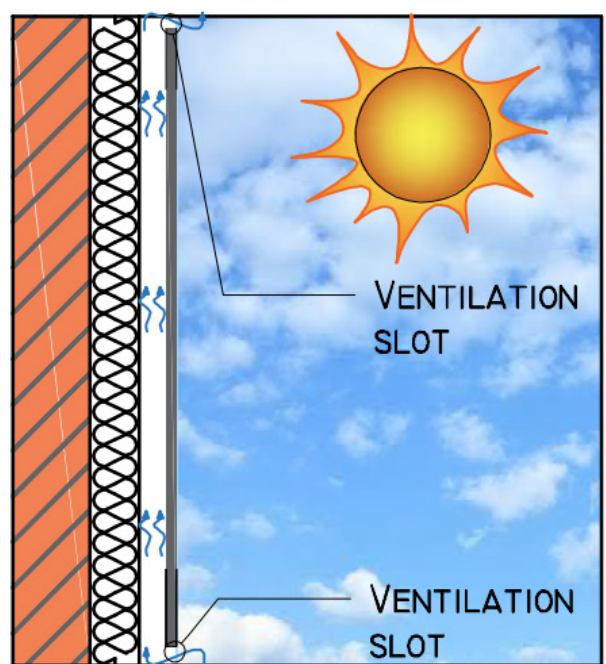

b)

Figure 3: Types of ventilated facades: a) with open joints; b) with closed joints [6].

and the environmental influences of snow, wind, and temperature. External facade claddings do not ensure the airtightness of the building, but only to a certain extent provide protection of the external surface of the wall to which the facade or insulation is attached. A ventilated facade is a complete set of individual components that make up a system solution. The standard specifying the requirements for the complete ventilated facade system is ETAG 034-1 [3], where the individual components of the entire ventilated facade system must additionally meet national requirements. The special feature of a ventilated facade is the air gap (also called ventilated space) between the external facade cladding and the insulation layer, or the supporting wall if no insulation layer is used. The ventilation space is according to ETAG 034-1 [3] at least $20 \mathrm{~mm}$, but locally it may be reduced to 5-10 $\mathrm{mm}$, depending on the cladding and substructure, provided that it is verified that this does not affect the efficiency function of the entire complete system. Literature sources specify ventilation space dimensions in the range of $20-50 \mathrm{~mm}$ [4], [5]. Some sources also quote higher values, e.g., from 40 to $100 \mathrm{~mm}$ [6]. A more important parameter, independent of the dimension of the ventilation space, is to adequately enable the flow of air through the ventilation space. This is ensured not only by the dimension of the ventilation space but also by the appropriate number of ventilation slots - allowing air to enter the space.

Because of the way air can enter and exchange in the ventilation space, we distinguish two types of ventilated facades: with closed joints, referred to as opaque ventilated facade, and open-joint ventilated facade. Examples of these ventilated facade technologies are shown in Figure 3 [6].

A ventilated facade ensures that the effect of heat transfer from the environment, especially on summer and sunny days, to the building interior is reduced. This is caused by limited thermal conduction. The higher efficiency of a ventilated facade, compared to an ETICS facade, in terms of limiting heat transfer through thermal conduction is shown in Figure 4. Thermal conduction, i.e., heat transfer through solids in the case of an ETICS facade, takes place through the entire surface, while in the case of a ventilated facade, it takes place only through consoles, which mediate between the external facade cladding and the external wall.

\section{Literature Overview}

Naboni in [7] shows that a ventilated facade is a very good solution in summer, reducing the heat build-up in the building. This is due to the reduction of conduction by solids. Naboni took a building in Milan as a baseline. During the study, the south wall of the building was taken as representative, in both summer and winter. In both seasons, the use of a ventilated facade resulted in benefits such as a lower exterior wall temperature on the inside in the summer and a higher exterior wall temperature on the inside in the winter.

The question should be asked, is a ventilated facade a good heat transfer limitation under all conditions? What happens in the case of windless conditions? Authors of the article [8] analyzed the airflow in the ventilation space of 


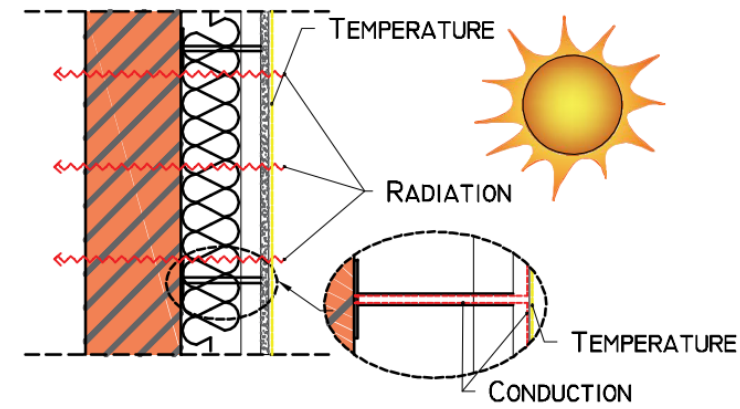

a)

Figure 4: Heat transfer in a) ventilated facade; b) ETICS facade.

a ventilated facade. In the study, three different situations of inflow velocity of air simulating wind were analyzed. The results of the simulations conducted revealed that in the absence of incoming air, the airflow in the ventilation space is generated only by the buoyancy effect, which is directly influenced by solar radiation. In addition, a correlation was noted between the external wind speed and the air speed inside the ventilation space. The authors in the paper [9] indicate for the sunny part of the building, energy savings in the range of $47-51 \%$ compared to an ETICS facade. Authors of [5] focus on the analysis of airflow in the facade with open and closed joints. The research methodology consisted in creating a 2D numerical model considering material and meteorological data and then analyzing the air vectors in the ventilation space. To verify the model, thermographic measurements were performed using an infrared camera in a reference building in Madrid. The numerical tests performed and the tests in the reference building showed that in the open-joint technology, the internal temperatures increase with the height of the building, and the increase in temperatures is greater than that in the closed-joint technology. On the other hand, with respect to temperatures in the whole envelope, closed joints give a higher temperature in the envelope - ventilation space, but it is better dissipated, resulting in lower heat transferred to the building. The simulation results also show that the greater the solar radiation, the more electricity needed to cool the building with air conditioning can be saved with this type of facade. After analyzing the airflow, it can be clearly stated that the airflow velocity inside the ventilation space in the case of open joints is about five times higher than that in the case of closed joints, and it is highly correlated with the height of the location of the intermediate ventilation slots, used to supply air to the interior of the ventilation space.

In scientific papers, we can also find considerations on heat recovery from ventilation spaces [9]. The authors

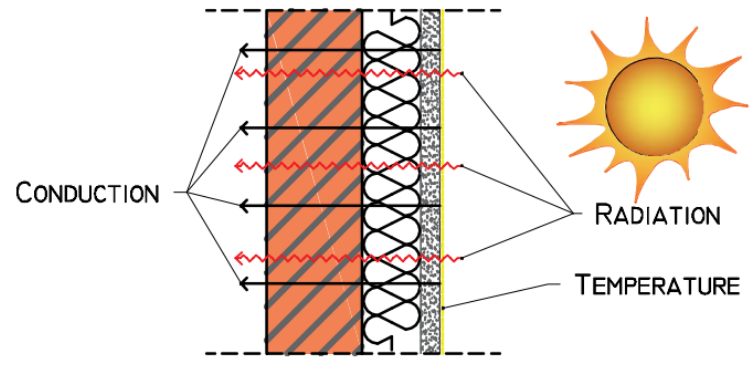

b)

used the simulation tools TRNSYS and TRNFlow for the study, and weather data recorded during the test period for the coldest and warmest seasons were used as input to the program. The experimental monitoring included measurements of an existing building in Valencia for a period of one year. By using temperature sensors in the experimental model, it was possible to read the temperature differences occurring in the envelope. The temperature from the numerical model was compared with the temperature results of the experimental model, at intervals of about 10 minutes. The comparison of the numerical model and the experimental model showed deviations in temperature results of about $15-20 \%$. Based on the study, the authors showed that by recovering heat from the ventilation space of the facade, it is possible to reduce the energy demand in the experimental building by almost $75 \%$, considering the analysis of the south, east, and west facades. It was also shown that it is possible to save electricity for the use of air conditioning by almost $10 \%$, taking into account the analysis of ventilated facades compared to airtight facades.

It should be noted that research is also ongoing on more complex system for integrating facade (also ventilated facade), called Trombe Wall [10], systems with supporting wall. Trombe Wall makes it even more possible to reduce the energy needed for the maintenance of buildings than only ventilation facade systems.

\section{Building a Numerical Model and Adopting Assumptions for the Simulation}

In order to solve the scientific question concerning the verification of the airflow in the ventilation space on the influence of the performance of the ventilated 
facade, numerical analyses were performed using CFD (Computational Fluid Dynamic) software and Ansys Fluent module based on Navier-Stokes equations. The choice of software was based on the experience presented in [8], [11], [12], [13], in which similar problems were solved using this software. Authors in the paper [13] while performing numerical analyses also performed their validation with experimental studies and the results confirmed the relevance of using this type of analysis. In this paper, we adopted k- $\varepsilon$ (RNG) as the numerical flow model, as discussed by Launder in [14]. On the other hand, Chen [15] showed that the accuracy of the flow model adopted in this way is good and applicable to this type of tasks. Thermal radiation model based on the study by Chui [16] was adopted as DO (discrete ordinates), which was presented as fast and accurate.

\subsection{Technological and material assumptions of the numerical model}

The problem of the efficiency of ventilated facades and the method of extracting air from the ventilation space are not well recognized in the scientific literature. The only general requirements for the minimum width of a ventilation space are indicated: for ETAG 034-1 [3], it is $20 \mathrm{~mm}$, but a constriction of $5-10 \mathrm{~mm}$ is permissible. Unfortunately, there is no information on the efficiency of removal of hot air from the ventilation space under different external wind conditions. It is assumed that there is always air movement in the ventilation space, at least to a minimum extent, since there is always air movement in the atmosphere. ETAG 034-1 [3] imposes on designers also an obligation to ensure adequate airflow in the ventilation space.

For the purposes of the article, numerical models were adopted using two types of ventilated facades: with closed joints and with open joints. These models were developed with identical materials, namely: the supporting wall was made of 240-mm-thick silicate blocks, thermal insulation was made of 150-mm-thick polyurethane, and the external cladding was made of fibre-cement boards in the so-called dark color and $20 \mathrm{~mm}$ thick. The total height of the model was assumed to be $4 \mathrm{~m}$. The models included a ventilation space of $50 \mathrm{~mm}$ between the insulation and the external cladding made of fibre-cement board. For the model with closed joints, air entered the ventilation space through two ventilation slots at the bottom and top of the outer cladding, each $30 \mathrm{~mm}$ wide. In the case of the model with open joints, air enters not only through the previously mentioned ventilation slots but also through intermediate ventilation slots, reproducing the facade panel assembly and located every approximately $1 \mathrm{~m}$, each $20 \mathrm{~mm}$ wide. The adopted model schemes are shown in Figure 5.

For the purpose of the case, the part of the facade without openings for windows and doors, at a height of one story, was taken into account. In the case of buildings, it is necessary to remember a number of thermal bridging due to window joinery and door frames, or structure attachment mount. These elements have a negative impact on the transmission of heat inside the building.

\subsection{Assumptions for the numerical model}

For the purposes of the numerical analysis, five variants of air inflow were assumed to simulate wind at the facade, with the following wind speeds: $0,2.5,5,10$, and $15 \mathrm{~m} / \mathrm{s}$. Additionally, the influence of temperature was taken into account, and this was done based on the standard: PN-EN 1991-1-5:2005: Eurocode 1: Actions on structures - Part 1-5: General actions - Thermal actions [4]. The computational situation was based on the effects of temperature and insolation during the summer. The facade was located in Poland and was situated on the south side due to the greatest insolation. It was assumed that this facade will be made in the so-called dark colors due to the greatest absorption of sunlight. Parameters related to such assumptions are as follows:

- $\quad$ Outdoor temperature $38^{\circ} \mathrm{C}(311.15 \mathrm{~K})$

- Indoor temperature $20^{\circ} \mathrm{C}(293.15 \mathrm{~K})$

- Additional temperature difference due to insolation $42^{\circ} \mathrm{C}$

- Total temperature acting on the facade at peak $38^{\circ} \mathrm{C}+$ $42^{\circ} \mathrm{C}=80^{\circ} \mathrm{C}(353.15 \mathrm{~K})$

\subsection{Numerical model}

Ansys Fluent in the Ansys Workbench module was used for the numerical study. The model was built as two-dimensional (2D). In order to represent the global conditions of airflow and exchange and heat transfer, the following model dimensions were assumed: width $2390 \mathrm{~mm}$ and height $4000 \mathrm{~mm}$. In the middle plane of the model, a wall was modeled so that there is air space on both sides of the wall. According to the authors, the model so adopted makes it possible to reproduce the global conditions of airflow (outdoors) and heat transfer. The wind is simulated by an inflow of air with a temperature equal to $311.15 \mathrm{~K}$, and an appropriate wind speed, depending on the case under consideration. In addition, a 


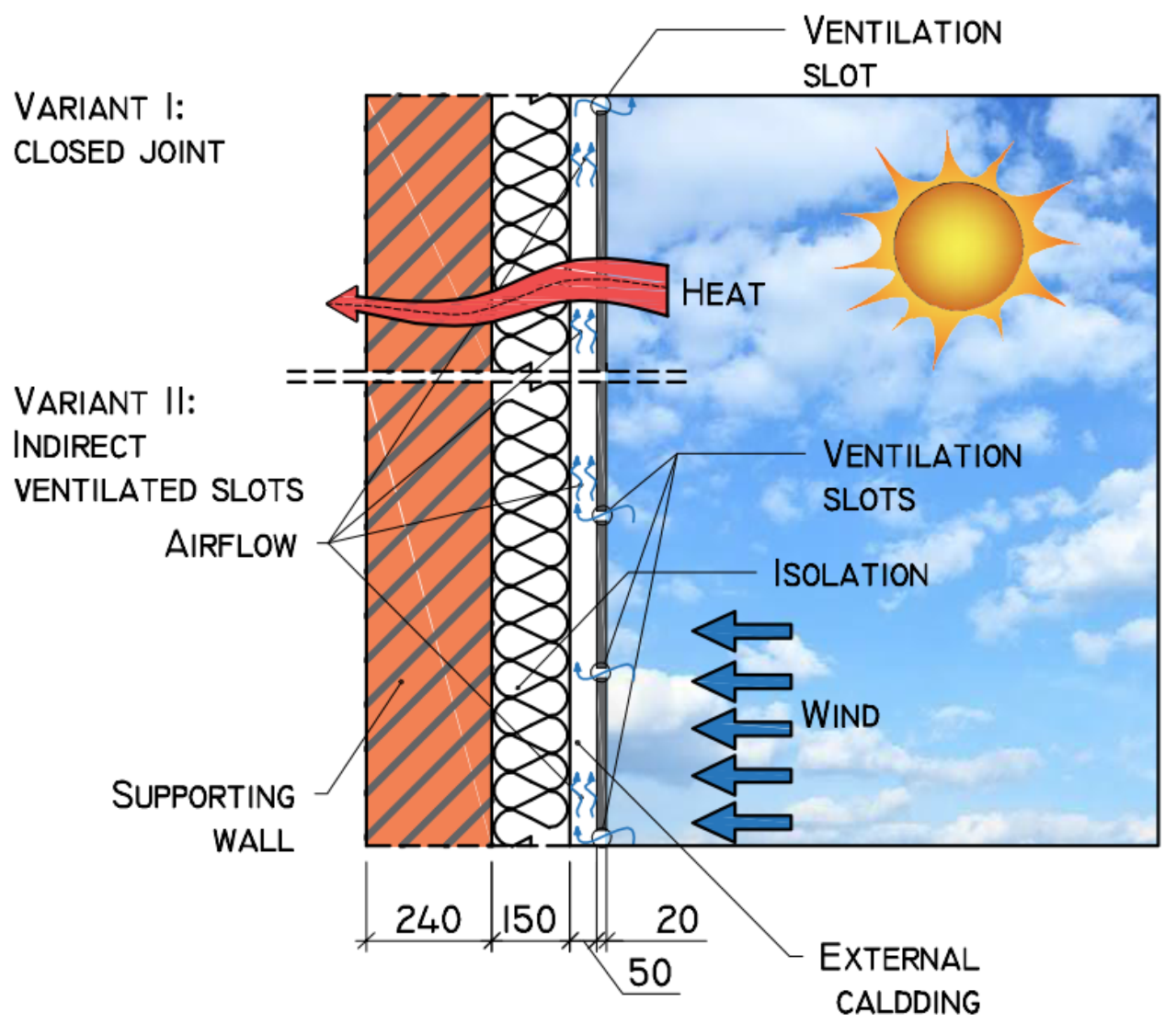

Figure 5: Facade diagrams for numerical simulations of ventilated facade.

corresponding temperature of $353.15 \mathrm{~K}$ was set at the outer edge of the fibre-cement board to simulate insolation. It was assumed that the conditions inside the building are constant, and the air inside has an initial temperature of $293.15 \mathrm{~K}$ and is not exchanged or cooled. Triangular threenode elements were used to create the finite element mesh. The dimensions of the individual finite elements were selected according to the location with sizes ranging from 1 to $50 \mathrm{~mm}$. Numerical simulation results.

\section{Results of Numerical Simulations}

In order to verify the scientific issue, measurement points were located in two technological variants of the ventilated facade: closed and open joints. Locations of points, in which temperature measurements were made, are shown in Figure 6.

Figure 7 presents the airflow for ventilated facade variants with closed (Figure 7(a) and (b)) and open joints (Figure 7(c) and (d)), for two different speeds of air inflow simulating the wind: 2.5 and $10 \mathrm{~m} / \mathrm{s}$. In the case of a ventilated facade with closed joints (Figure 7(a) and (b)), aberrations are noticeable at the lower ventilation slot - the flow there assumes a disturbed shape, while the airflow inside the ventilation space is constant: laminar. In the case of facades with open joints, it is noticeable that intermediate ventilation slots also participate in the supply of air inside the ventilation space. Additionally, it is possible to separate the ventilation slots which supply air (lower and lower - intermediate) and those which receive air (upper and upper - intermediate).

Airflow also influences the temperatures inside the ventilation space, which translates into room temperatures as well. Maps of the course of temperatures are presented in Figure 8, for variants of models identical as assumed in Figure 7. On the example of Figure 8 a) and c), it may be noticed that a larger number of ventilation slots allows for supplying larger amounts of air inside the ventilation space. The temperatures inside the ventilation space are more favorable for the ventilated facade with closed joints; the temperature inside is 313.8 (for a wind speed of 2.5 $\mathrm{m} / \mathrm{s}$ ), vs. $315.6 \mathrm{~K}$ on average for open joints. The trend of lower temperature inside the ventilation space applies to 


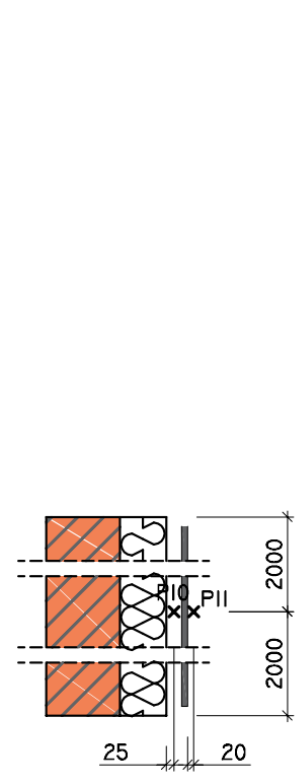

a)

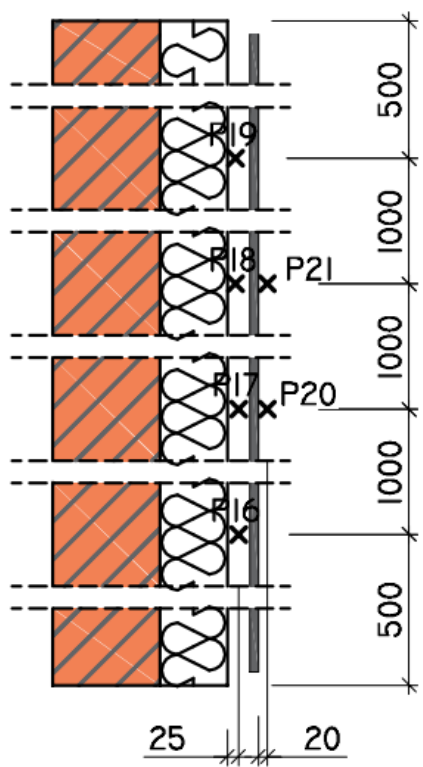

b)

Figure 6: Location of temperature measurement points: a) closedjoint ventilated facade; b) open-joint ventilated facade. all cases of wind speed. This is due to the smaller amount of air supplied through the ventilation slots and the greater transfer of cold through the wall from inside the space.

A tabular summary of temperatures and flow velocities for variants of a ventilated facade in the technology of closed and open joints, depending on the speed of the incoming air, is presented in Table 1. For a ventilated facade with open joints, more measuring points have been adopted in order to obtain as large an overview as possible of the phenomena occurring inside the ventilation space and on the external side of the facade cladding.

As the results below show, as the height in the facade increases, the temperature inside decreases, and this may indicate that ventilated facades are an excellent solution in buildings of high height.

For the ventilated facade with closed joints as shown in Figure 6, air velocity and temperature were measured at two points. As shown in Figure 9, the temperature in the ventilated space at point 10 , even with the minimum design air velocity of $2.5 \mathrm{~m} / \mathrm{s}$ coming in at the facade, shows very good heat dissipation. The temperature at this point is $2.3 \mathrm{~K}$ higher than the temperature at the air coming into the facade at $5 \mathrm{~m} / \mathrm{s}$. For higher incoming air velocities, the temperature differences inside the ventilation space

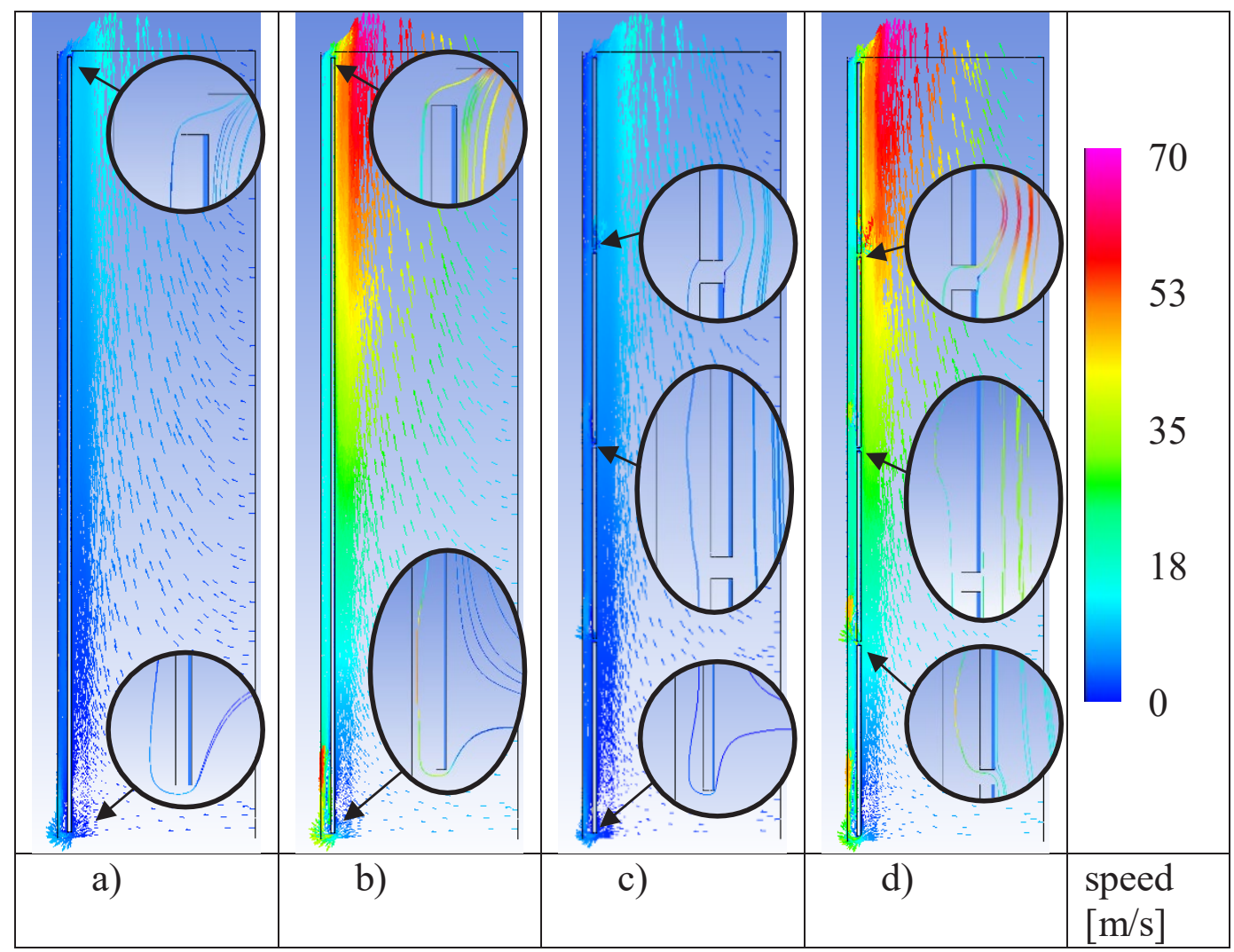

Figure 7: Airflow for individual numerical models: a) closed joint: $2.5 \mathrm{~m} / \mathrm{s}$; b) closed joint: $10 \mathrm{~m} / \mathrm{s}$; c) open joint: $2.5 \mathrm{~m} / \mathrm{s}$; d) open joint: $10 \mathrm{~m} / \mathrm{s}$. 


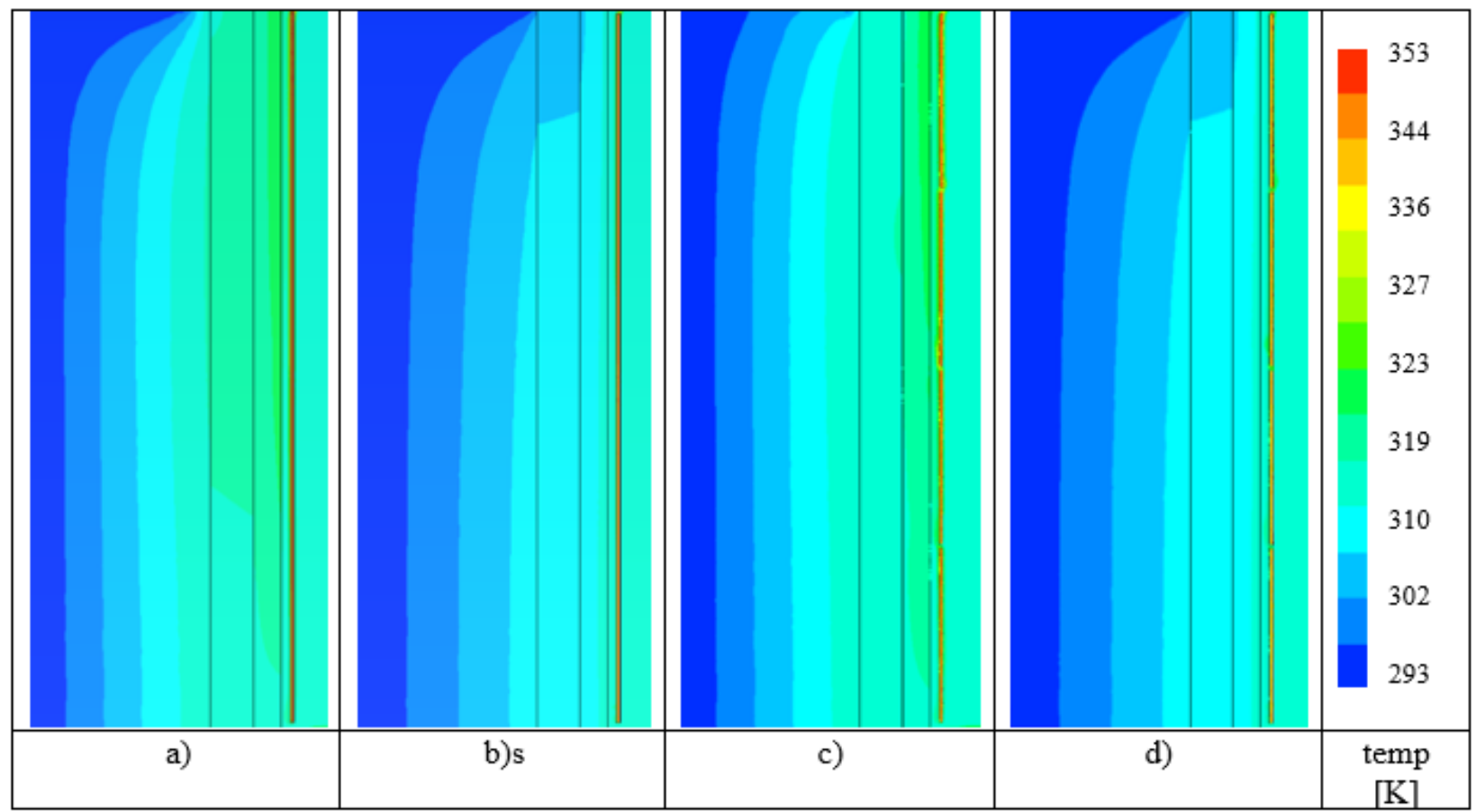

Figure 8: Temperature course for individual numerical models: a) closed joint: $2.5 \mathrm{~m} / \mathrm{s} ;$ b) closed joint: $10 \mathrm{~m} / \mathrm{s} ; \mathrm{c}$ ) open joint: $2.5 \mathrm{~m} / \mathrm{s} ; \mathrm{d}$ ) open joint: $10 \mathrm{~m} / \mathrm{s}$.

Table 1. Summary of temperatures and air velocities for measurement points.

\begin{tabular}{|c|c|c|c|c|c|c|c|c|c|c|c|c|c|c|c|c|c|}
\hline & \multirow{3}{*}{$\begin{array}{l}\text { Wind } \\
\text { speed }\end{array}$} & \multicolumn{2}{|c|}{ Point 10} & \multicolumn{2}{|c|}{ Point 11} & \multicolumn{2}{|c|}{ Point 16} & \multicolumn{2}{|c|}{ Point 17} & \multicolumn{2}{|c|}{ Point 18} & \multicolumn{2}{|c|}{ Point 19} & \multicolumn{2}{|c|}{ Point 20} & \multicolumn{2}{|c|}{ Point 21} \\
\hline & & Temp & Speed & Temp & Speed & Temp & Speed & Temp & Speed & Temp & Speed & Temp & Speed & Temp & Speed & Temp & Speed \\
\hline & & $\overline{\mathrm{K}}$ & $\mathrm{m} / \mathrm{s}$ & $\mathbf{K}$ & $\mathrm{m} / \mathrm{s}$ & $\mathbf{K}$ & $\mathrm{m} / \mathrm{s}$ & K & $\mathrm{m} / \mathrm{s}$ & $\mathrm{K}$ & $\mathrm{m} / \mathrm{s}$ & K & $\mathrm{m} / \mathrm{s}$ & $\mathbf{K}$ & $\mathrm{m} / \mathrm{s}$ & $\mathrm{K}$ & $\mathrm{m} / \mathrm{s}$ \\
\hline \multirow{5}{*}{$\begin{array}{l}\text { Close } \\
\text { joint }\end{array}$} & 0.0 & 351.8 & 0.0 & 352.7 & 0.0 & & & & & & & & & & & & \\
\hline & 2.5 & 313.8 & 4.6 & 315.1 & 6.0 & & & & & & & & & & & & \\
\hline & 5.0 & 311.5 & 7.8 & 311.7 & 13.9 & & & & & & & & & & & & \\
\hline & 10.0 & 311.4 & 14.8 & 311.4 & 27.8 & & & & & & & & & & & & \\
\hline & 15.0 & 311.3 & 32.0 & 311.3 & 41.7 & & & & & & & & & & & & \\
\hline \multirow{5}{*}{$\begin{array}{l}\text { Open } \\
\text { joint }\end{array}$} & 0.0 & & & & & 351.9 & 0.0 & 351.8 & 0.0 & 351.7 & 0.0 & 351.7 & 0.0 & 352.7 & 0.0 & 352.7 & 0.0 \\
\hline & 2.5 & & & & & 313.4 & 3.8 & 316.0 & 5.2 & 317.2 & 5.6 & 317.2 & 4.0 & 314.6 & 4.5 & 314.4 & 7.4 \\
\hline & 5.0 & & & & & 312.3 & 7.8 & 313.2 & 11.2 & 313.0 & 10.5 & 312.4 & 7.4 & 311.2 & 11.1 & 312.0 & 16.5 \\
\hline & 10.0 & & & & & 311.8 & 15.6 & 312.5 & 21.7 & 312.4 & 20.2 & 312.0 & 14.1 & 311.1 & 22.3 & 311.8 & 33.1 \\
\hline & 15.0 & & & & & 311.7 & 23.4 & 312.2 & 32.2 & 312.2 & 29.9 & 311.8 & 20.8 & 311.2 & 33.2 & 311.7 & 49.7 \\
\hline
\end{tabular}

increase minimally. In the case of air velocity in the ventilation space, the increase is significant in relation to the incoming air velocity, but it does not really increase the efficiency of better removal of hot air. In the case of Point 11 , located outside from the facade cladding, the incoming air velocity has a greater effect on the temperature removal from the surface of the facade cladding. The difference between the temperature at inflow velocities of 2.5 and $5 \mathrm{~m} / \mathrm{s}$ is $3.4 \mathrm{~K}$. At successively higher inflow velocities, the temperature, as in the previous variant, is almost constant. The airflow on the outside of the facade cladding increases linearly with respect to the incoming air simulating wind. The temperature and flow inside the ventilation space for Point 11 are shown in Figure 10. 


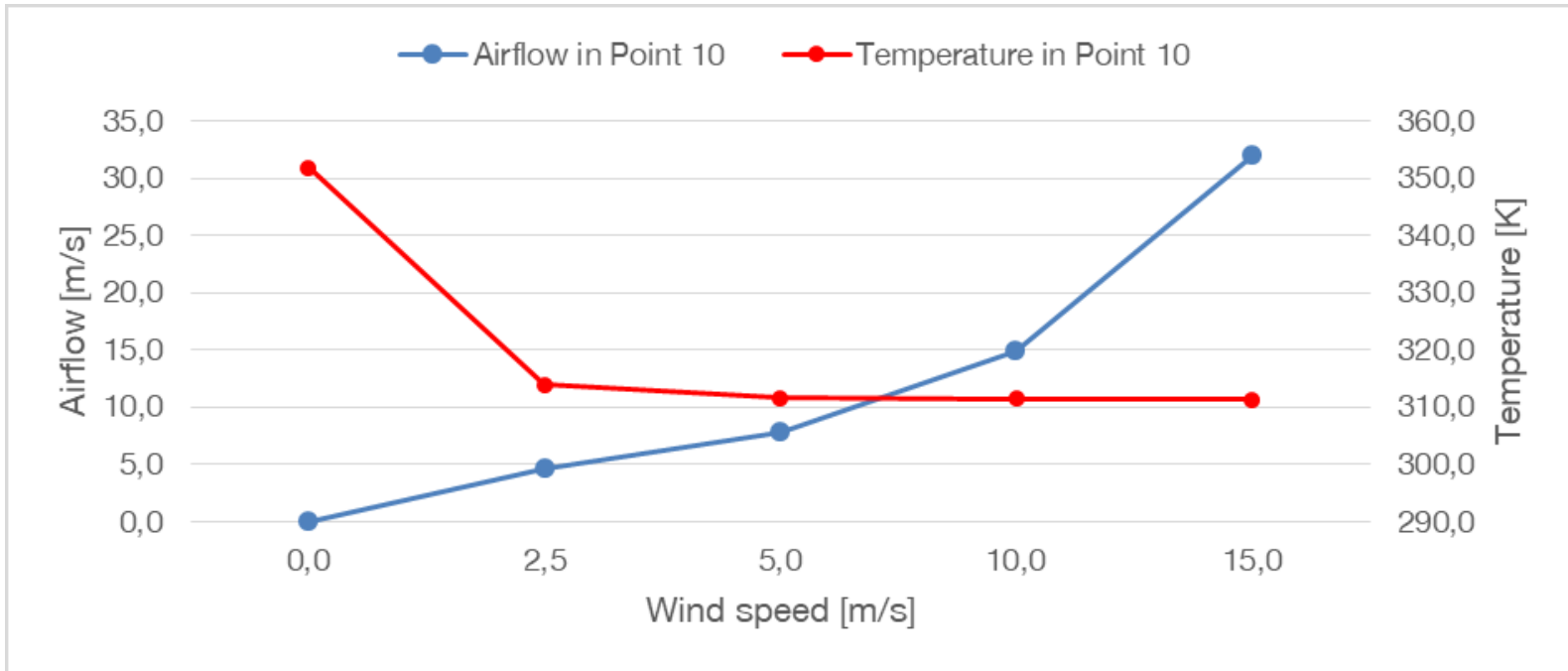

Figure 9: Compilation of temperature and air velocity for the ventilated facade with closed joints at Point 10.

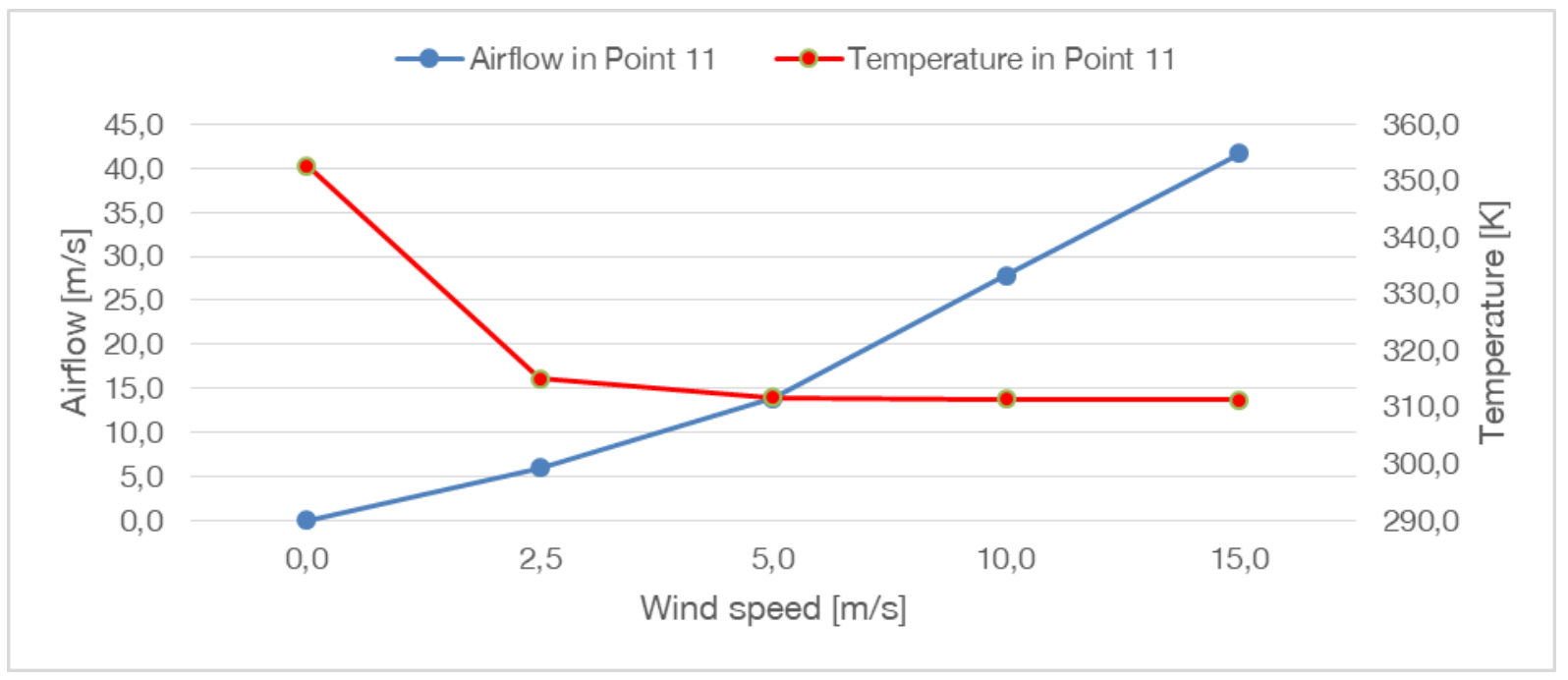

Figure 10: Compilation of temperature and air velocity for the ventilated facade with closed joints at Point 11.

For the ventilated facade with open joints, four measuring points inside the ventilation space and two measuring points on the outside of the facade cladding were considered. Similar trends in the behavior of the temperature change and the difference in airflow inside the ventilation space and the flows in the openjoint technology as in the variant with closed joints are observed. At the speed of $2.5 \mathrm{~m} / \mathrm{s}$ of wind inflow to the facade, the temperature inside the ventilation space is in the range of 313.4-317.2 $\mathrm{K}$. On the other hand, for the velocity of $5 \mathrm{~m} / \mathrm{s}$ wind inflow to the elevation, the temperature inside the space is in the range of 311.2-313.0 $\mathrm{K}$. The results are shown graphically in Figure 11. The temperature stabilization inside the ventilation space is achieved at $5 \mathrm{~m} / \mathrm{s}$ elevation wind inflow velocity, and the subsequent increase in the inflow wind velocity does not increase the efficiency of heat removal from the ventilation space. This causes that higher velocities do not improve the efficiency of heat removal from the ventilation space, so the heat transmission to the building interior is not reduced. At incoming wind speeds to the facade above 5 $\mathrm{m} / \mathrm{s}$, no significant changes are observed.

In the case of airflow on the exterior side of the facade cladding for the variant with open joints, the analysis was carried out for two measurement points. For this location, even the smallest selected air inflow simulating wind which was a wind speed of $2.5 \mathrm{~m} / \mathrm{s}$ into the facade - results in nearly identical temperatures. Higher velocities of air 


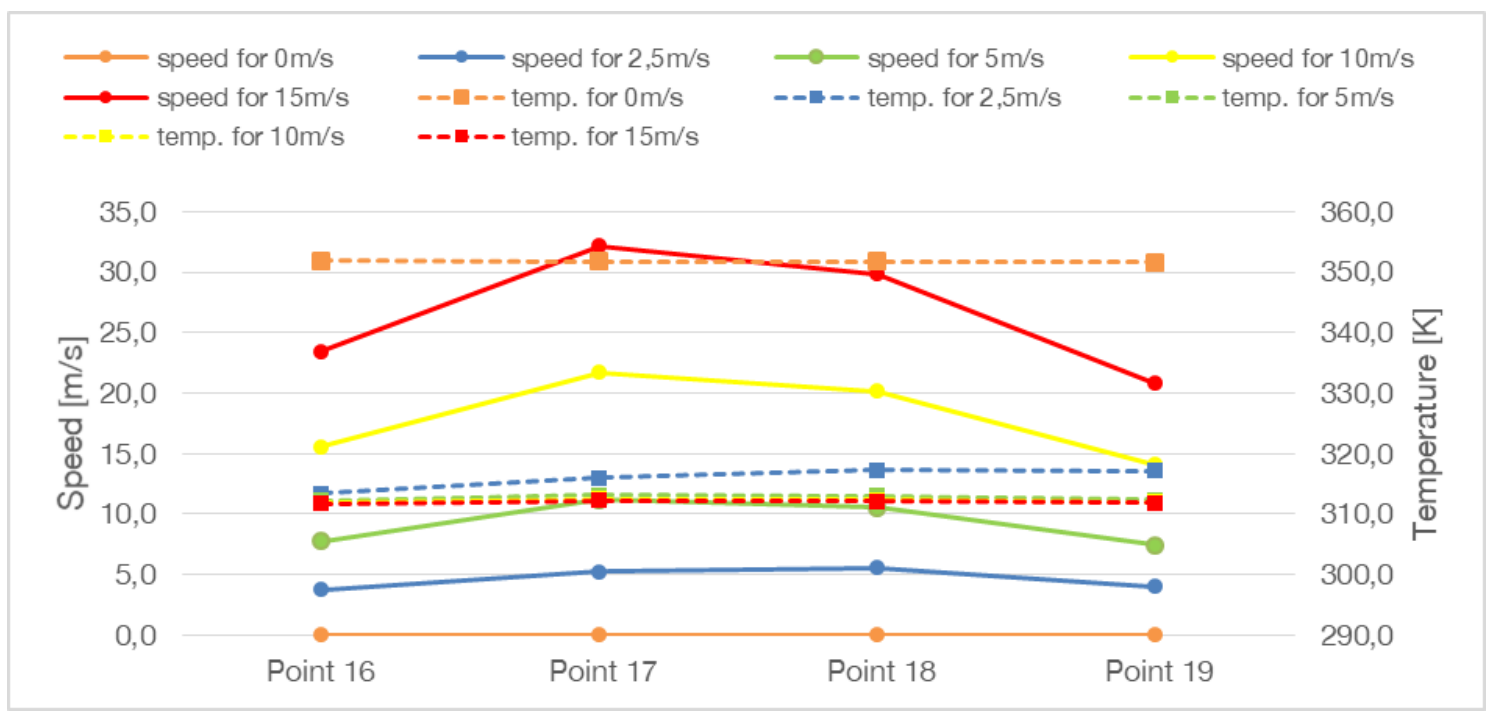

Figure 11: Compilation of temperature and airflow velocity for individual measurement points inside the ventilation space for a ventilated facade with closed joints.

inflow to the facade caused minimal temperature changes within the facade cladding on the external side, which may suggest that even minimal wind effectively removes heat from this location.

In the previous steps, the analysis of the removal of air with a higher temperature from the ventilation space was carried out, but the question occurred to the authors of the study: does it influence the temperature inside the room? For the purpose of this analysis, a number of consecutive measuring points were selected on the inner side of the wall (room side) as well as on the individual wall layers. All measurement points for the course of the temperature for the facade ventilated in both technologies - open and closed joints - are presented in Figure 13.

All the results obtained from the tests are summarized in Table 2. It is noticeable that in the two technological variants of the ventilated facade, the speed of the incoming air on the facade of $2.5 \mathrm{~m} / \mathrm{s}$ is insufficient for good removal of hot air; on the other hand, an increase in the speed decreases the heat transmission.

The course of the temperature for particular technological variants of the ventilated facade, as well as for different speeds of the air coming to the facade simulating the wind, is presented in Figs 14 and 15, based on the results contained in Table 2. It can be observed that for both closed and open joints, the wind speed prevailing outside affects the efficiency of heat removal from the ventilation space, and in turn affects the lower temperatures inside the room. As an example, the temperature difference in Point 7 for the speed of 2.5 and $5 \mathrm{~m} / \mathrm{s}$ is about $7 \mathrm{~K}$, and the situation is very similar for both technological variants of the ventilated facade. In addition, it is noticeable that in spite of much better air supply and removal in the ventilated facade with open joints, the temperature course for both variants is similar, which at first seemed impossible. The temperature behind the facade cladding stabilizes in both variants in the case of a $5 \mathrm{~m} / \mathrm{s}$ wind inflow to the facade, and higher speeds do not increase the effectiveness of the ventilated facade.

\section{Conclusions}

Ventilated facades fit in very well with the increasing demands placed on buildings in the field of sustainable construction. The thermal comfort they provide increases their use not only in regions of the world with high temperatures but also in regions with the so-called mild climate.

Numerical studies confirm that the effectiveness in terms of heat removal from the ventilation space is dependent on the wind speed prevailing outside. The so-called open-joint technology, despite higher temperatures in the ventilation space, is more efficient in terms of lower heat transfer to the inside of the room, not only in windless weather but also at lower wind speeds prevailing outside $-2.5 \mathrm{~m} / \mathrm{s}$. In the case of wind velocity coming into the facade of $5 \mathrm{~m} / \mathrm{s}$, the performance of ventilated facades in the variants of closed and open joints reaches similar values. Subsequent increase in the velocity of wind inflow to the facade outside minimally affects the efficiency of heat removal through the ventilated space, 


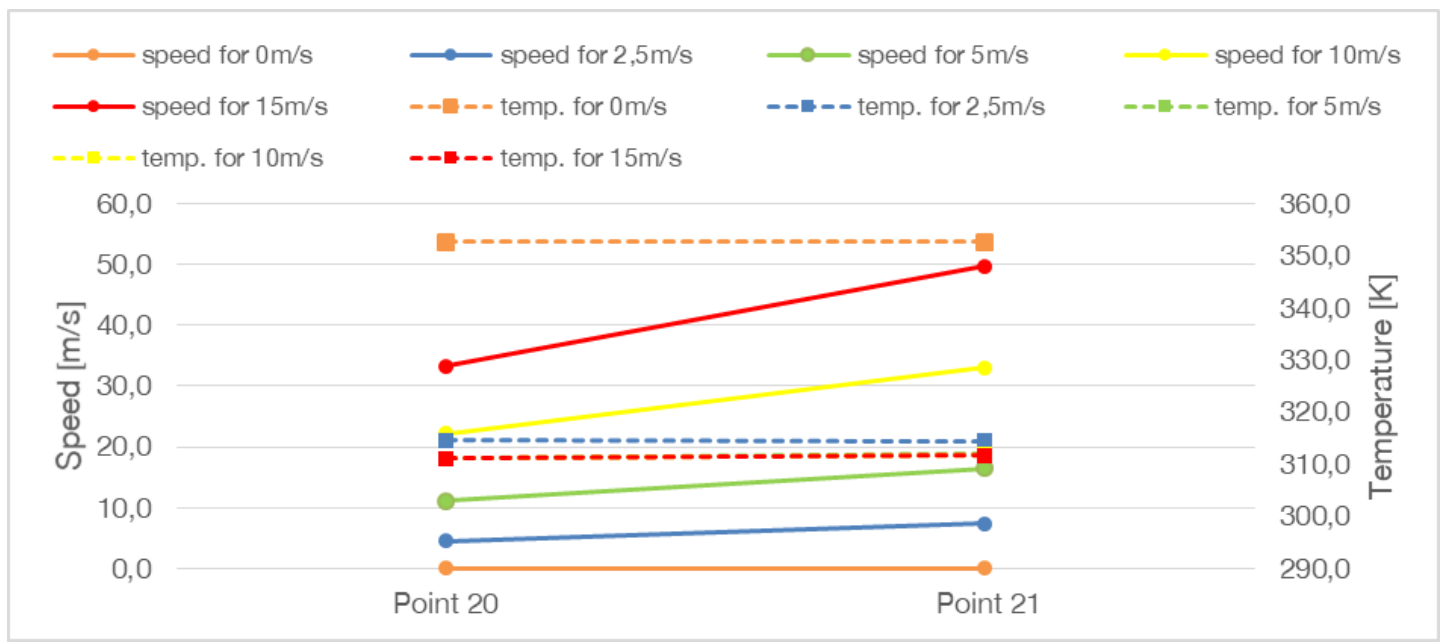

Figure 12: Compilation of temperature and air velocity for individual measurement points outside the cladding for a ventilated facade with closed joints.

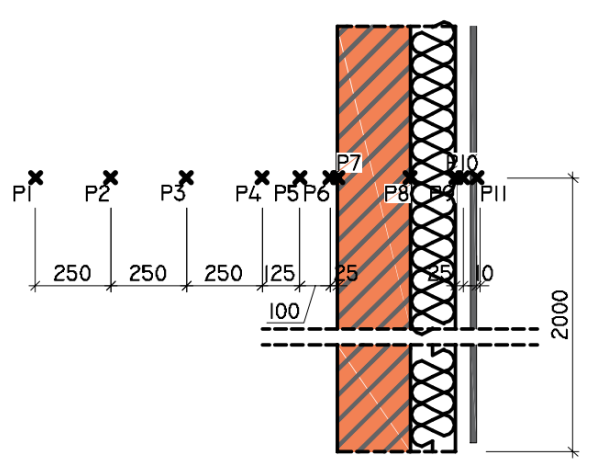

a)

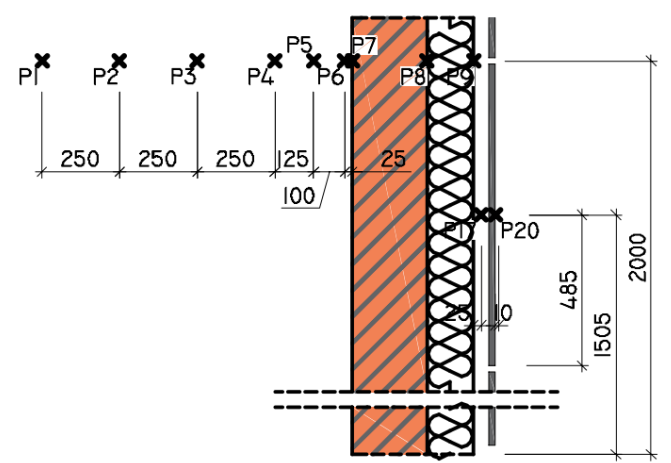

b)

Figure 13: Location of temperature measurement points: a) closed-joint ventilated facade; b) open-joint ventilated facade.

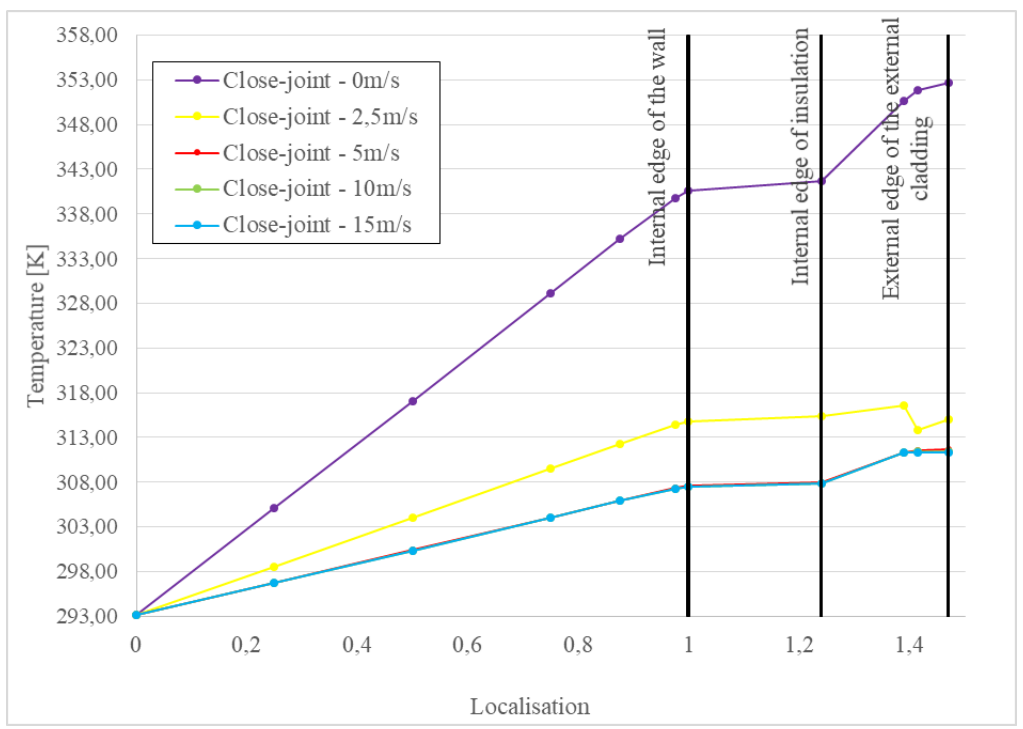

Figure 14: Temperature overview for the control points of the close-joint facade. 
Table 2: Compilation of temperatures for measurement points inside the room and within the wall.

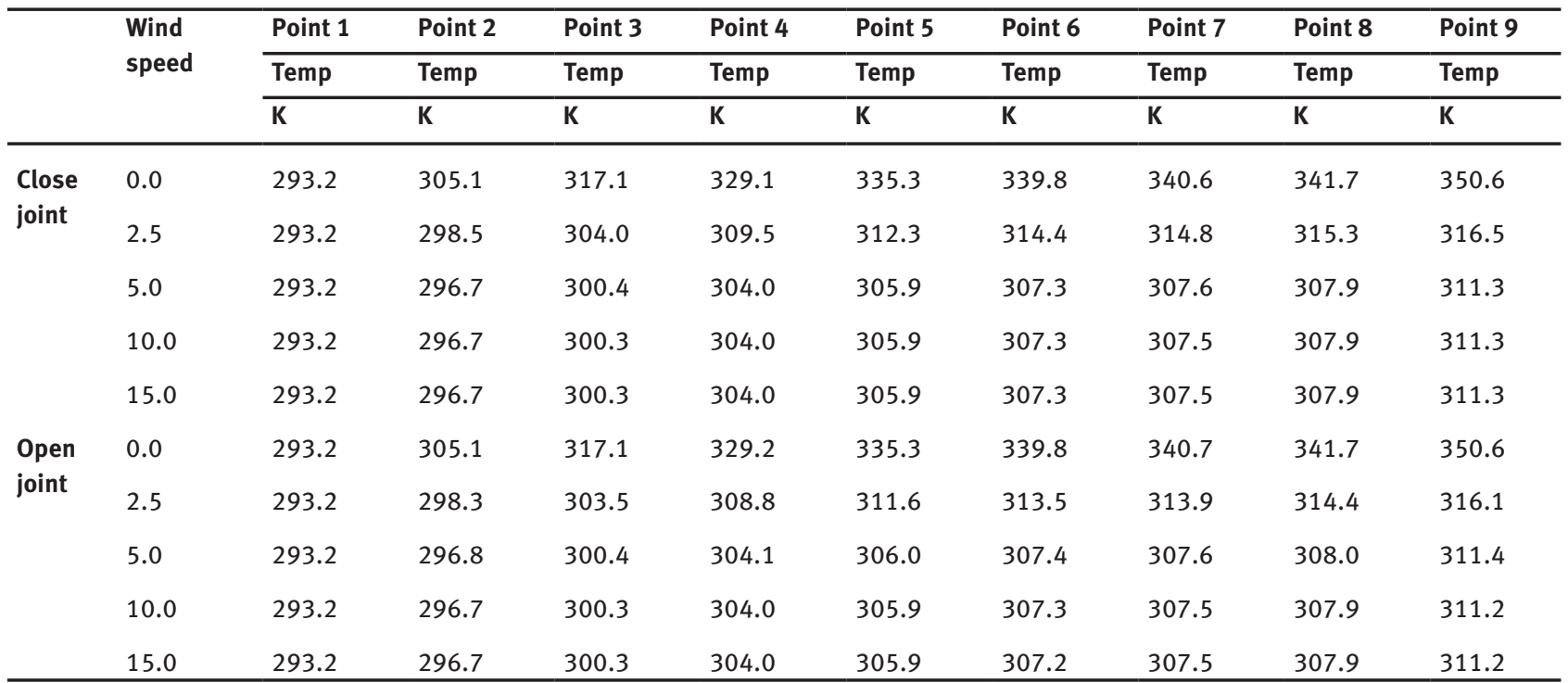

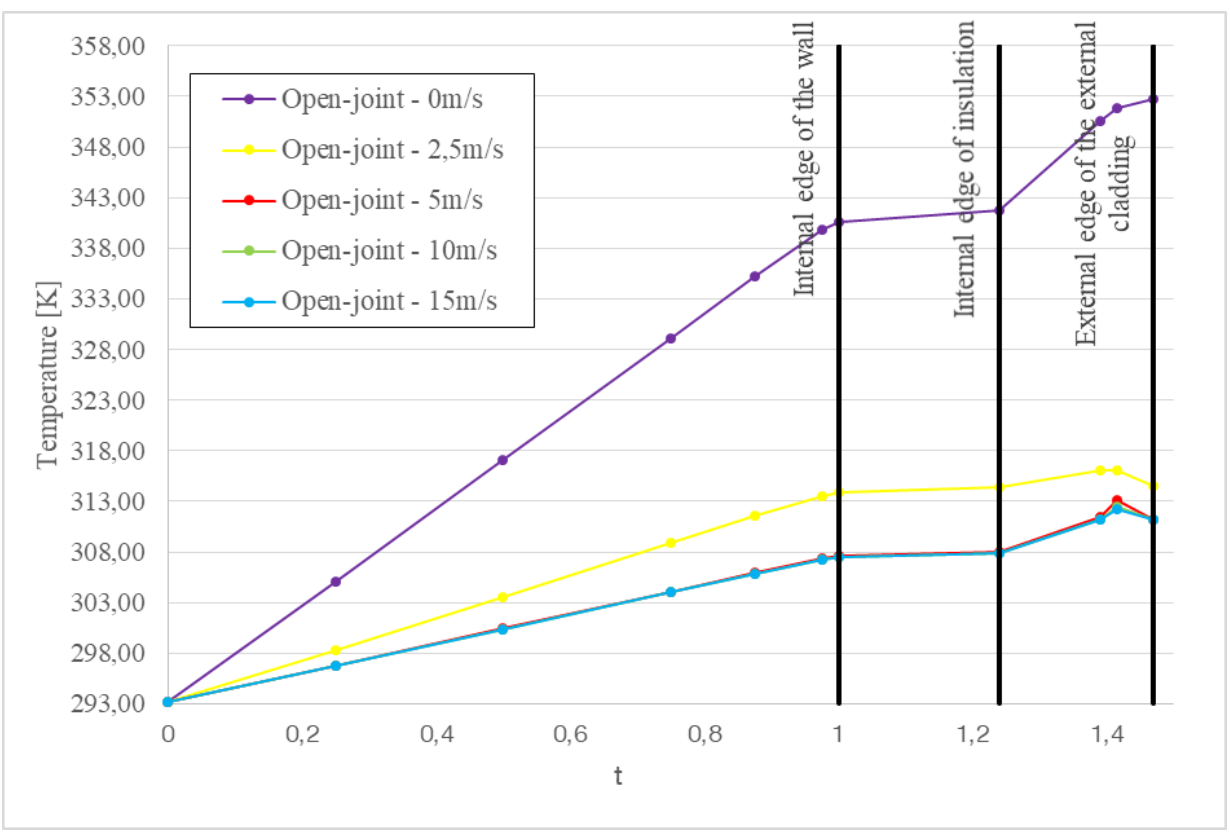

Figure 15: Temperature overview for the control points of the open-joint facade.

thus reducing heat transmission to the interior. The analyses carried out in this study have also shown that intermediate ventilation slots, used in a ventilated facade with open joints, have a significant effect on air exchange in the ventilation space. In the example studied, the intermediate ventilation slots, which are responsible for supplying and removing air from the ventilation space, can be clearly distinguished. These slots also introduce disturbances and aberrations in the flow inside the ventilation space, but this influence is much smaller than the benefits of their presence.

It is also very important to consciously use ventilated facades on buildings that will not be shielded from incoming air in order to achieve the greatest possible efficiency. Conscious use of this facade technology, along with appropriate urban design of cities, can help reduce the energy needed to cool buildings in the summer. The authors intend to continue this research. 


\section{References}

[1] Website: https://ec.europa.eu/eurostat/.

[2] A.-J. Romana i N. Maciej, „Wskaźnikowa ocena komfortu w budynkach mieszkalnych zlokalizowanych w klimacie umiarkowanym," Izolacje, nr 6, pp. 2-7, 2016.

[3] EOTA ETAG 034 Part 1: Ventilated Cladding Kits comprising Cladding components and associated fixings.

[4] EN 1991-1-5: Eurocode 1: Actions onstructures - Part 1-5: General actions - Thermal actions.

[5] C. Sanjuan, M. J. Suárez, M. González, J. Pistono i E. Blanco, Energy performance of an open-joint ventilated facade compared with a conventional sealed cavity façade, [ [ Solar Energy 85, pp. 1851-1863, 2011.

[6] M. Ibañez-Puy, M. Vidaurre-Arbizu, J. A. Sacristán-Fernádez i C. Martín-Gómez, gopaque Ventilated Façades: Thermal and energy performance review.," Renewable and Sustainable Energy Reviews, Volume 79, pg. 180-191. doi: 10.1016/j. rser.2017.05.059., nr 79, pp. 180-191, 2017.

[7] E. Naboni, „Ventilated opaque walls - A performance simulation method and assessment of simulated performance," w Seminar Notes at Lawrence Berkeley National Laboratory Environmental Energy Technologies Division Berkeley, California, USA, May 28 2007.

[8] A. Gagliano, F. Nocera i S. Aneli, „Thermodynamic analysis of ventilated facades under different wind conditions in summer period," Energy and Buildings 122, pp. 131-139, 2016.

[9] C. Aparicio-Fernández, J.-L. Vivancos, P. Ferrer-Gisbert i R. Royo-Pastor, 国Energy performance of a ventilated façade by

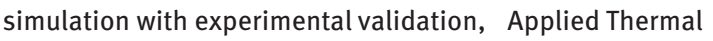
Engineering 66, pp. 563-570, 2014.

[10] J. Szyszka, J. Kogut, I. Skrzypczak i W. Kokoszka , „Selective Internal Heat Distribution in Modified Trombe Wall," IOP Conference Series: Earth and Environmental Science, tom 4, nr 95, 2017.

[11] M. Chereches, N. C. Chereches i S. Hudisteanu, „Numerical modeling of solar radiation inside ventilated double-skin facades," International journal of heat and technology vol. 33, No. 4, pp. 246-254, 2015.

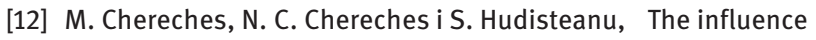
of different flow velocities on the heat transfer inside a ventilated façade, [ R Revista Romana de Inginerie Civila Vol. 5, No.1, 2014.

[13] L. Cirillo, D. Di Ronza, V. Fardella, O. Manca i S. Nardini, „Numerical and experimental investigations on a solar chimney integrated in a building façade., International Journal of Heat and Technology 33 (4), pp. 246-254, 2015.

[14] B. Launder i D. Spalding, ,The numerical computation of turbulent flows. Computer Methods.," Computer Methods in Applied Mechanics and Engineering 3, pp. 269-289, 1974.

[15] Q. Chen, „Comparison of different $\mathrm{K}-\varepsilon$ models for indoor airflow computations.," Numerical Heat Transfer, Part B, 28, pp. 353-369, 1995.

[16] E. Chui i G. Raithby, „Computation of radiant heat transfer on a non-orthogonal mesh using the finite-volume method.," Numerical Heat Transfer, Part B, 23, pp. 269-288, 1993.

[17] Website: http://www.breaam.com

[18] Website: http://leed.usgbc.org/leed.html

[19] O. Kopyłow, Elewacje wentylowane - Warunki Techniczne Wykonania i Odbioru Robót Budowlanych B14/2015.

[20] A. Gagliano, F. Nocera and S. Aneli, "Thermodynamic analysis of ventilated facades under different wind conditions in summer period,” Energy and Buildings 122, pp. 131-139, 2016.

[21] C. Aparicio-Fernández, J.-L. Vivancos, P. Ferrer-Gisbert and R. Royo-Pastor, "Energy performance of a ventilated façade by simulation with experimental validation," Applied Thermal Engineering 66, pp. 563-570, 2014.

[22] ANSYS Fluent Theory Guide.

[23] ANSYS Fluent User's Guide.

[24] EOTA ETAG 034 Part 2: Cladding Kits comprising Cladding components, associated fixings, subframe and possible insulation layer.

[25] K. Schabowicz, Elewacje wentylowane Technologia Produkcji i metody badania płyt włóknisto-cementowych, Wrocław: Oficyna Wydawnicza Politechniki Wrocławskiej, 2018.

[26] EOTA ETAG 034 Part 2: Cladding Kits comprising Cladding components, associated fixings, subframe and possible insulation layer.

[27] M. Suárez, C. Sanjuan, A. Gutiérrez, J. Pistono and E. Blanco, "Energy evaluation of an horizontal open joint ventilated façade," Applied Thermal Engineering 37, pp. 302-313, 2012. 